Article

\title{
Glycyrrhizin Protects the Diabetic Retina against Permeability, Neuronal, and Vascular Damage through Anti-Inflammatory Mechanisms
}

\author{
Li Liu, Youde Jiang and Jena J. Steinle *(1) \\ Visual, and Anatomical Sciences, Department of Ophthalmology, Wayne State University, Detroit, MI 48202, USA \\ * Correspondence: jsteinle@med.wayne.edu; Tel.: +1-313-577-9731; Fax: +1-313-577-3125
}

Received: 31 May 2019; Accepted: 29 June 2019; Published: 2 July 2019

\begin{abstract}
Damage associated molecular pattern (DAMPs), such as high mobility group box 1 (HMGB1), may be involved in retinal inflammation in response to high glucose. To test whether HMGB1 inhibition could protect the diabetic retina, C57BL/6J mice were made diabetic and treated with glycyrrhizin, a HMGB1 inhibitor, for up to six months. Measurements of permeability, neuronal, and vascular changes were done, as well as assessments of HMGB1, tumor necrosis factor alpha $(\mathrm{TNF} \alpha)$, and interleukin-1-beta (IL1 $\beta$ ) levels. Retinal endothelial cells (REC) treated with glycyrrhizin had reduced IL1 $\beta$ and cleaved caspase 3 levels. Data also demonstrate that glycyrrhizin effectively reduced HMGB1 levels throughout the retina, as well as maintained normal retinal permeability and retinal capillary coverage. Glycyrrhizin maintained normal cell numbers in the ganglion cell layer and prevented thinning of the retina at two months. These histological changes were associated with reduced reactive oxygen species, as well as reduced HMGB1, TNF $\alpha$, and IL1 $\beta$ levels. The data strongly imply that HMGB1 inhibition prevented diabetic retinal changes through anti-inflammatory pathways.
\end{abstract}

Keywords: diabetic retinopathy; inflammation; endothelial cells; glycyrrhizin; high mobility group box 1 (HMGB1)

\section{Introduction}

Despite ongoing attempts to prevent and/or delay progression of diabetic retinopathy, it remains the leading cause of blindness in younger adults. Anti-vascular endothelial growth factor (VEGF) therapy is effective for some patients with macular edema or proliferative disease. However, little is available for early stage disease.

For the past two decades, diabetes and diabetic retinopathy have become increasingly linked to chronic inflammation (Joussen et al., 2004 [1], Tang and Kern 2011 [2]). Recent discoveries have shown associations between retinal pathology and a large number of inflammatory mediators (tumor necrosis factor alpha (TNF $\alpha)$, interleukin-1-beta (IL1 $\beta)$, inducible nitric oxide synthase inducible nitric oxide synthase (iNOS), Fas ligands) (Joussen et al., 2009 [3], Vincent and Mohr 2007 [4], Romeo et al., 2002 [5], Du, Sarthy, and Kern 2004 [6]) and innate immune components (Toll-like receptor 2 and 4 (TLR2 and TLR4)) (Wang et al., 2015 [7], Rajamani and Jialal 2014 [8], Berger et al., 2016 [9], Tang and Kern 2011 [2]). In addition, some have suggested that diabetes may represent a form of sterile inflammation, leading to activation of high mobility group box 1 (HMGB1), a damage associated molecular pattern (DAMP) (Tsung, Tohme, and Billiar 2014 [10], Andersson and Tracey 2011 [11]).

We chose to focus on HMGB1, as research in one-month diabetic rats showed that glycyrrhizin, a HMGB1 inhibitor, significantly reduced HMGB1, extracellular signal-related protein kinases 1 and 2 (ERK1/2), caspase-3, and glutamate levels (Abu El-Asrar et al., 2014 [12]). Additionally, studies on 
receptor for advanced glycation end products (RAGE) knockout mice showed that ischemia/reperfusion (I/R) significantly increased HMGB1 levels in the retina (Dvoriantchikova et al., 2011 [13]). Inhibition of HMGB1 reduced neuronal cell loss in these mice. In other ocular targets, results in a model of Pseudomonas aeruginosa keratitis showed that glycyrrhizin significantly reduced HMGB1 levels and bacterial load (Ekanayaka et al., 2016 [14]). Glycyrrhizin is a natural anti-inflammatory and antifungal factor, which inhibits HMGB1 chemoattractant and mitogenic activities through direct binding to HMGB1 and interacting with the two shallow surfaces on the arms of the HMGB1 A and B boxes (Mollica et al., 2007 [15]). Studies using recurrent seizure models showed that inhibition of HMGB1 is protective against epileptic events (Morales-Sosa et al., 2018 [16]). We recently used glycyrrhizin to show that acute inhibition of HMGB1 protected against I/R-induced damage to the retina (Liu, Jiang, and Steinle 2017 [17]). However, no studies have investigated the chronic effects of glycyrrhizin in the diabetic retina.

We hypothesized that long-term inhibition of HMGB1 using glycyrrhizin would protect the retina against diabetes-induced damage.

\section{Experimental Section}

\subsection{Mice}

Male C57BL/6J mice were purchased from Jackson Laboratories at eight weeks of age. Mouse experiments were approved by the Institutional Animal Care and Use Committee at Wayne State University (Protocol\# 17-07-301) and adhere to the Animal Policy of the Association for Research in Vision and Ophthalmology. Diabetes was induced by $60 \mathrm{mg} / \mathrm{kg}$ injections of streptozotocin dissolved in citrate buffer for up to five consecutive days. Control mice received citrate buffer only. Glucose measurements were done each week, with glucose levels $>250 \mathrm{mg} / \mathrm{dL}$ accepted as diabetic. Mice were not fasted before glucose measurements, and all measurements were taken on $\sim 5 \mu \mathrm{L}$ blood samples measured by a handheld measurement device. Table 1 provides body weights and glucose measurements from all mice. Five mice each were used for permeability, neuronal, and vascular analyses. Five mice at both two and six months were used for protein analyses.

A subset of the control and diabetic mice will then be treated with glycyrrhizin in their drinking water (150 mg/kg/day) (Abu El-Asrar et al., 2014 [12]). Mice were maintained on the drinking water for six months. Water consumption was measured weekly for the first month, and then twice a week to ensure that mice were consuming the correct dose of drug. Based on mouse water consumption, glycyrrhizin did not appear to change the taste of the water. We also measured HMGB1 levels at both two and six months to demonstrate that the dose of glycyrrhizin was effectively reducing HMGB1 levels.

\subsection{Measurement of Permeability Changes in the Retina}

Permeability analyses were completed on control and diabetic mice alone and following glycyrrhizin treatment at two and six months. For fluorescein angiography (FA), the pupil was dilated with tropicamide ophthalmic solution, followed by anesthesia via ketamine and xylazine. After mice were deeply anesthetized, $150 \mu \mathrm{L}$ of AK-FLUOR $(1 \% \mathrm{~W} / \mathrm{V}$, AKORN, INC, Lake Forest, IL, USA) was injected intraperitoneally (IP). Retinal vessel leakage was imaged by a Micron IV (Phoenix Research Labs, Pleasanton, CA, USA). Images were taken less than 5 min after injection of the dye.

For a more quantitative measurement of permeability, additional mice were transfused with $200 \mu \mathrm{L}$, Evans blue (0.5\% in saline, Sigma Aldrich) via the tail vein. Forty-five minutes after infusion, mice were euthanized with $\mathrm{CO} 2$, with retinas were carefully removed, placed into $100 \mu \mathrm{L}$ formamide, and incubated for $48 \mathrm{~h}$ at $55^{\circ} \mathrm{C}$. Tubes were then centrifuged and transferred to a 96-well plate for measurements of the absorbance at measured at 610 (Radu and Chernoff 2013 [18]). 


\subsection{Measurement of Neuronal Damage}

After two months of diabetes or diabetes + glycyrrhizin treatment, a subset of each group of mice was sacrificed for measurements of neuronal thickness, as we have done previously with the exception of staining with hematoxylin and eosin instead of toluidine blue (Steinle et al., 2009 [19]). Analyses of retinal thickness and cell numbers for each retinal layer were assessed from the same regions in each retina, as we have done in the past (Zhang et al., 2012 [20], Steinle et al., 2009 [19]).

\subsection{Measurement of Degenerate Capillaries}

After six months of diabetes or treatment, the remaining mice were sacrificed. Some mice were processed for measurements of degeneration of capillaries as we have done in the past (Liu, Jiang, and Steinle 2016 [21], Veenstra et al., 2015 [22]).

\subsection{Measurement of Reactive Oxygen Species}

Protein lysates from all groups of mice at both two and six months of diabetes and treatment were processed for measurement of reactive oxygen species (ROS) using the 2'-7'-Dichlorodihydrofluorescein diacetate (DCFDA) method. Briefly, equal protein from each group was loaded into a black 96-well plate and treated with the DCFDA in triplicate and read on a fluorescent plate reader set with an excitation of $485 \mathrm{~nm}$ and emission at $530 \mathrm{~nm}$. Some wells were left blank, and some wells only received the DCFDA reagent. The blanks and dye only wells were subtracted from the raw data (Piippo et al., 2018 [23]). Data are plotted as the fluorescence intensity. In addition to the measurement of ROS using the DCFDA method, we also performed Western blotting to measures of 4-HNE to determine whether glycyrrhizin reduced lipid peroxidation in the retina of mice.

\subsection{Retinal Endothelial Cells (REC) Cultures}

Primary human retinal endothelial cells (REC) were purchased from Cell Systems Corporation (CSC, Kirkland, Washington, DC, USA). Cells were grown in basal glucose medium supplemented with microvascular growth factors (MVGS), $10 \mu \mathrm{g} / \mathrm{mL}$ gentamycin, and $0.25 \mu \mathrm{g} / \mathrm{mL}$ amphotericin B (Invitrogen, Carlsbad, CA, USA). Once cells reached confluence, some dishes were moved to Cell Systems high glucose medium. Only dishes prior to passage 6 were used. Cells were quiesced by incubating in high or normal glucose medium without MVGS for $24 \mathrm{~h}$ prior to experimental use. REC in normal $(5 \mathrm{mM})$ and high glucose $(25 \mathrm{mM})$ were treated with glycyrrhizin $(2 \mathrm{mM}$ for $2 \mathrm{~h}$ ) (Matsui et al., 2004 [24]).

\subsection{Western Blotting}

At both two and six months of diabetes and treatment or REC treatment with glycyrrhizin, whole retinal/cell lysates were collected into lysis buffer containing protease and phosphatase inhibitors. Equal amounts of protein from the cell extracts were separated on the pre-cast tris-glycine gel (Invitrogen, Carlsbad, CA, USA), blotted onto a nitrocellulose membrane. After blocking in TBST (10 mM Tris- $\mathrm{HCl}$ buffer, $\mathrm{pH} 8.0,150 \mathrm{mM} \mathrm{NaCl}, 0.1 \%$ Tween 20$)$ and $5 \%(w / v)$ bovine serum albumin (BSA), the membranes were treated with an HMGB1 (1:500, ab227168) or 4-HNE (1:500, ab46545) (Abcam, Cambridge, MA, USA) or beta actin-HRP (1:2000, sc-47778, Santa Cruz Biotechnology, Santa Cruz, CA, USA) primary antibodies. Antigen-antibody complexes were detected by chemiluminescence reagent kit (Thermo Scientific, Pittsburgh, PA, USA). Data was acquired using an Azure C500 (Azure Biosystems, Dublin, CA, USA). Western blot analyses were done using Image Studio Light software.

\subsection{Enzyme-Linked Immosorbent Assay}

A TNF $\alpha$ enzyme-linked immunosorbent assay (ELISA) (Fisher Scientific, Pittsburgh, PA, USA) was completed according to manufacturer's instructions with the exception that samples were exposed to primary antibody for $24 \mathrm{~h}$, and $100 \mu \mathrm{g}$ of protein was used to insure equal protein amounts in all 
wells. The IL1 $\beta$ ELISA was completed according to manufacturer's instructions with the exception that $120 \mu \mathrm{g}$ protein loaded into all wells, and the primary antibody was incubated overnight. A cleaved caspase 3 ELISA was done following manufacturer's instructions (Cell Signaling, Danvers, MA, USA), with equal protein loaded to allow for measurements using optical density (O.D.) values.

\subsection{Statistics}

A one-way ANOVA with Student Newman Keul's post-hoc test was used for data analyses on animal samples. A Kruskal-Wallis analysis was done for cell culture data. All analyses were done using Prism software by GraphPad (San Diego, CA, USA). Some data numbers may not reach the $80 \%$ level by power analyses; however, the numbers used for these studies are standard for the field (Abcouwer et al., 2010 [25], Al-Shabrawey et al., 2008 [26]). Data are mean \pm standard error of mean unless stated otherwise. $p<0.05$ was considered statistically significant. For all data, $n=$ the number of mice or cells per treatment group. A representative blot is given for Western blot data.

\section{Results}

\subsection{Glycyrrhizin Reduced Blood Glucose Levels at Two Months, but Not Six Months}

Table 1 data demonstrates that type 1 diabetic mice treated with glycyrrhizin for two months had a reduction in blood glucose levels compared to diabetic mice receiving no treatment $(p<0.05,1$-way ANOVA analyses). This was not maintained at six months. Our findings are different from published data at one month of glycyrrhizin, which found no differences in blood glucose at one month of diabetes and glycyrrhizin treatment in rats (Abu El-Asrar et al., 2014 [12]). Since we used the same dosing for glycyrrhizin, the reason for these differences is unclear. Our data do agree with other diabetic models, including periodontal disease (Akutagawa et al., 2019 [27]) and kidney disease (Wang et al., 2014 [28]). Nonetheless, in our studies, glycyrrhizin only had a short-term effect on blood glucose in these mice, so the chronic actions of glycyrrhizin on the retina likely result from other mechanisms.

Table 1. Data are mean \pm standard deviation. ${ }^{*} p<0.05$ vs ctrl, ${ }^{\#} p<0.05$ Vs. Diabetes. Ctrl, control. Diabetes, Gly, glycyrrhizin.

\begin{tabular}{ccccccccc}
\hline & \multicolumn{2}{c}{ Ctrl } & \multicolumn{2}{c}{ Ctrl + Gly } & \multicolumn{2}{c}{ Diabetes } & \multicolumn{2}{c}{ Diabetes + Gly } \\
\hline & BW $(\mathrm{g})$ & BG & BW (g) & BG & BW (g) & BG & BW (g) & BG \\
\hline $8 \mathrm{~W}$ & $25.6 \pm 2.2$ & $113 \pm 12$ & $25.8 \pm 1.9$ & $109 \pm 6.7$ & $25.2 \pm 2.0$ & $110 \pm 8.1$ & $25.3 \pm 1.8$ & $108 \pm 7.2$ \\
2 m Diabetes & $32 \pm 2$ & $109 \pm 8$ & $30 \pm 1.9$ & $110 \pm 6.8$ & $26 \pm 1.4^{*}$ & $397 \pm 119^{*}$ & $28 \pm 1.2$ & $278 \pm 46^{\# *}$ \\
6 m Diabetes & $35.6 \pm 2.6$ & $110 \pm 12.6$ & $33.5 \pm 2$ & $129 \pm 21.2$ & $25.5 \pm 2.9^{*}$ & $538 \pm 73.6^{*}$ & $26.2 \pm 3.5$ & $502 \pm 101^{*}$ \\
\hline
\end{tabular}

BW = body weight, $\mathrm{BG}=$ blood glucose.

\subsection{Glycyrrhizin Reduced Diabetes-Induced Permeability at Both Two and Six Months}

To investigate changes in retinal permeability due to diabetes, we performed fluorescein angiography and Evan's blue measurements at two months and six months of diabetes in all groups. Figure $1 \mathrm{~A}$ shows the angiography results at two months. The data demonstrate increased leakage in the type 1 diabetic group, which is reduced with glycyrrhizin treatment. This is quantified in Figure 1B using Evan's blue ( ${ }^{*} p<0.05$ via one-way ANOVA). At six months, we see the same pattern of increased leakage due to diabetes (Figure 1C), which is reduced by glycyrrhizin treatment, both in angiography and using Evan's blue methods (Figure 1D, $p<0.05$ ). Glycyrrhizin had limited effects on permeability in the control retina. 


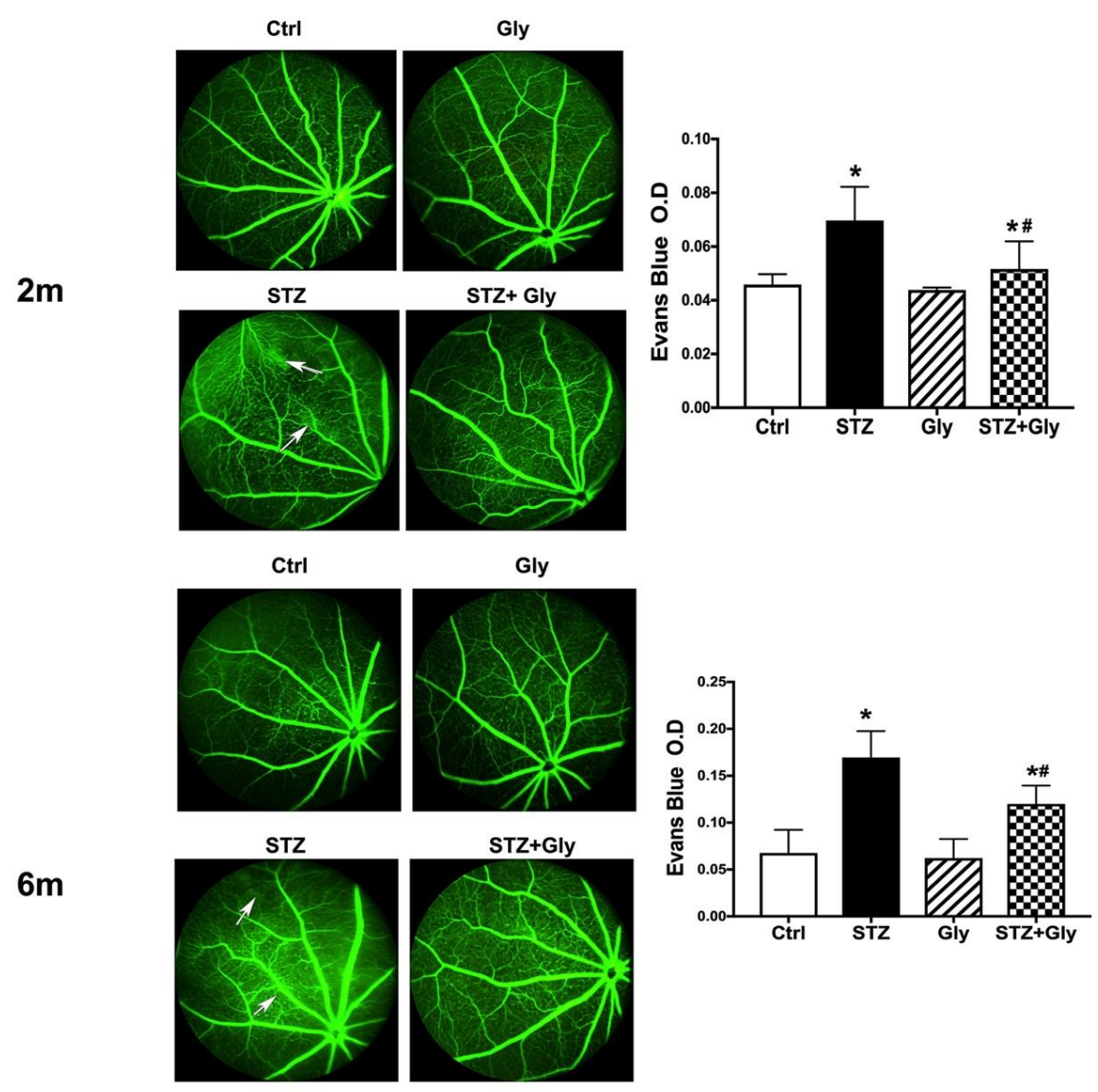

Figure 1. Fluorescein angiography (left) and Evan's blue analyses (right) from control mice (Ctrl), control mice treated with glycyrrhizin (Gly), diabetic mice (STZ), and diabetic mice treated with glycyrrhizin (STZ + Gly) at two months (top) and six months (bottom). Arrows point to areas of leakage. ${ }^{*} p<0.05$ vs. ctrl, $\# p<0.05$ vs. Diabetes. $n=5$ for each group.

\subsection{Neuronal Measurements Were Increased in Mice Receiving Glycyrrhizin Compared to Diabetic Only} Retina at Two Months

To investigate whether glycyrrhizin protected the retina against neuronal damage, we measured retinal thickness and cell numbers in the ganglion cell layer after two months of diabetes or diabetes and glycyrrhizin treatment, and analyzed data using a one-way ANOVA. Figure 2 shows that the type 1 diabetic retina is much thinner than control mice, control mice treated with glycyrrhizin, or diabetic mice treated with glycyrrhizin. Figure $2 B$ is quantitation of retinal thickness showing that glycyrrhizin significantly increased retinal thickness in diabetic mice $(p<0.05)$. Figure $2 C$ shows that glycyrrhizin treatment also increased the cell numbers in the ganglion cell layer compared to diabetic mice $(p<0.05)$. Glycyrrhizin alone did not alter neuronal measurements. 
A.

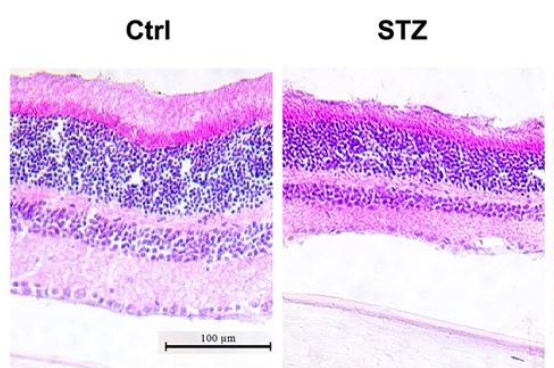

Gly

STZ+Gly

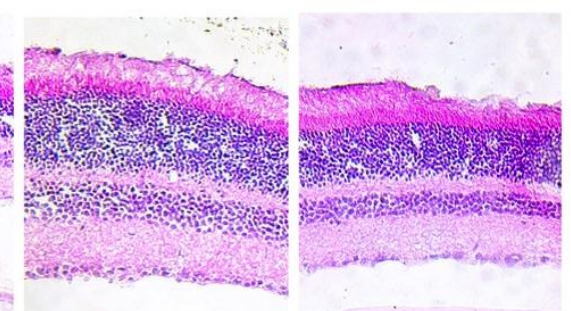

B.

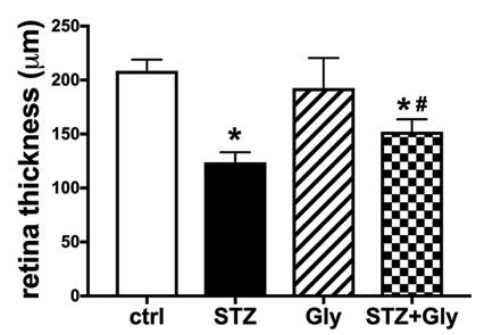

C.

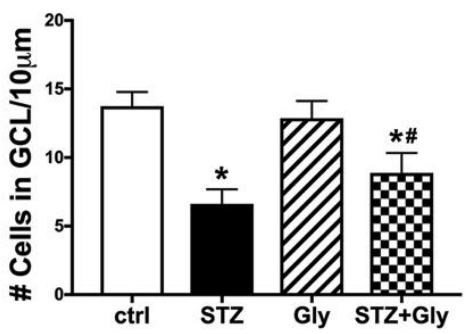

Figure 2. Hematoxylin and eosin for neuronal changes at two months of treatment. (A) Are representative images from control mice (Ctrl), control mice treated with glycyrrhizin (Gly), diabetic mice (STZ), and diabetic mice treated with glycyrrhizin (STZ + Gly). (B) Shows quantification of retinal thickness, and (C) is data on cell numbers in the ganglion cell layer (GCL). ${ }^{*} p<0.05 \mathrm{vs.} \mathrm{ctrl,} \# p<0.05$ vs. Diabetes. $n=5$ for each group.

\subsection{Glycyrrhizin Protected the Retinal Vasculature against Diabetes-Induced Injury at Six Months}

Diabetes causes the formation of degenerate capillaries after six months of exposure to high glucose (Zheng et al., 2007 [29], Zhang et al., 2012 [20]). We wanted to ascertain if glycyrrhizin could reduce retinal vascular damage. Figure 3 shows that diabetes significantly increased the numbers of degenerate capillaries, which was reduced by glycyrrhizin treatment $(p<0.05)$. Data were analyzed using a one-way ANOVA. Control mice treated with glycyrrhizin had no response to treatment.

Ctri

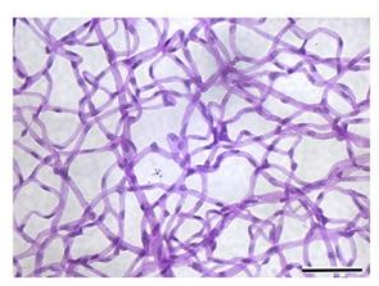

STZ

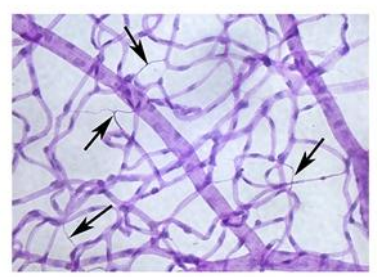

Gly

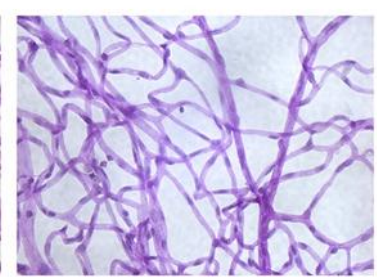

STZ+Gly

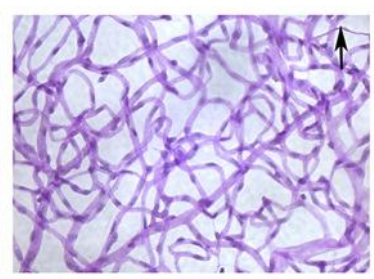

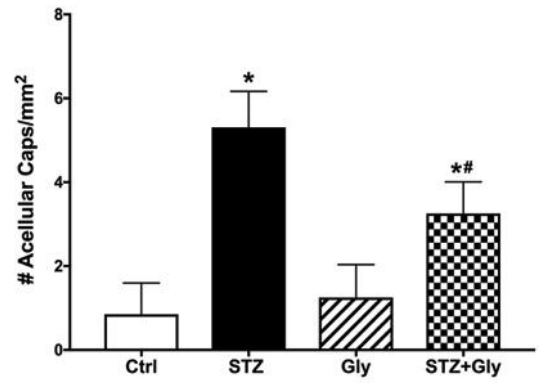

Figure 3. Vascular changes in the diabetic retina. Measurement of degenerate capillaries from control mice (Ctrl), control mice treated with glycyrrhizin (Gly), diabetic mice (STZ), and diabetic mice treated with glycyrrhizin (STZ + Gly). Representative images are presented on the left, with quantification on the right. Arrows point to degenerate capillaries. ${ }^{*} p<0.05$ vs. ctrl, $\# p<0.05$ vs. diabetes. $n=5$ for each group. Scale bar is $50 \mu \mathrm{m}$. 
3.5. Glycyrrhizin Significantly Reduced Reactive Oxygen Species Levels in Retina Lysates at Both Two and Six Months

Retinal damage from diabetes is reported to be caused by a significant increase in ROS production (Tang and Kern 2011 [2], Brownlee 2001 [30]). Therefore, we investigated whether glycyrrhizin could reduce ROS production in whole retinal lysates. Figure 4A,B shows that glycyrrhizin significantly reduced ROS levels in the diabetic retina, with limited effects in the control retina based on analyses using a one-way ANOVA. It is noted that total ROS levels were reduced at six months vs. two months in these mice. However, the rationale for this finding will be explored in the future. To further confirm the actions of glycyrrhizin on the retina, we also measured 4-HNE levels, a marker of lipid peroxidation. Figure $4 C, D$ show that diabetes increased lipid peroxidation in the retina, which was inhibited by glycyrrhizin treatment $(p<0.05)$.

A.

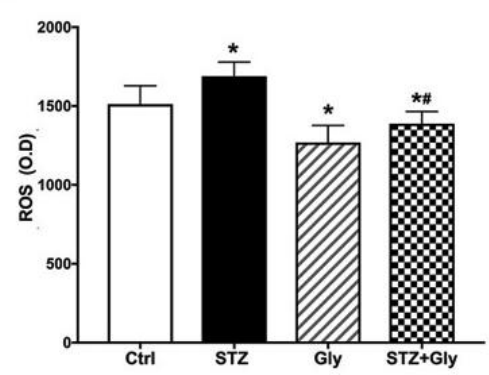

C.

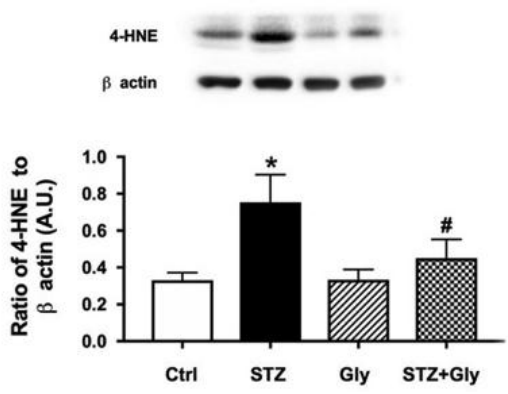

B.

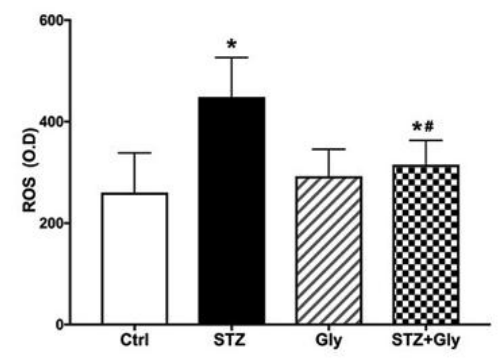

D.

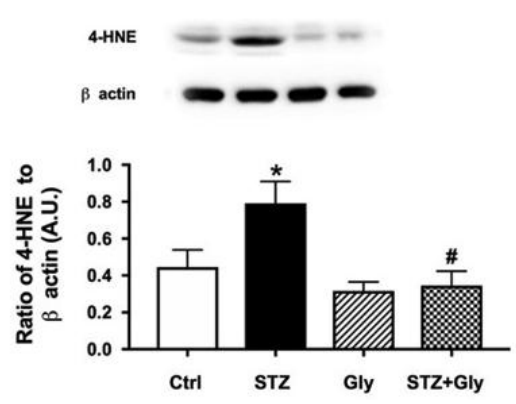

Figure 4. Reactive oxygen species (ROS) measurement in diabetic mice. (A) is at two months and (B) is measurement of ROS in control mice (Ctrl), control mice treated with glycyrrhizin (Gly), diabetic mice (STZ), and diabetic mice treated with glycyrrhizin (STZ + Gly). (C,D) show 4-HNE levels in the same groups. ${ }^{*} p<0.05$ vs. ctrl, $\# p<0.05$ vs. diabetes. $n=5$ for each group.

3.6. Diabetes Increased HMGB1 Levels, TNF $\alpha$, and IL1 $\beta$ Levels in the Retina, Which Was Reduced Following Glycyrrhizin Treatment

We previously showed that HMGB1 and inflammatory mediators are increased in REC grown in high glucose (Liu, Jiang, and Steinle 2017 [17]). However, we wanted to expand those findings into the diabetic retina. Figure 5 shows that diabetes increased HMGB1 (A), TNF $\alpha$ (B), and IL1 $\beta$ (C) levels in the diabetic retina at both two (top) and six months (bottom), which were significantly reduced by systemic treatment with glycyrrhizin ( $p<0.05$, one-way ANOVA analyses). 
A.
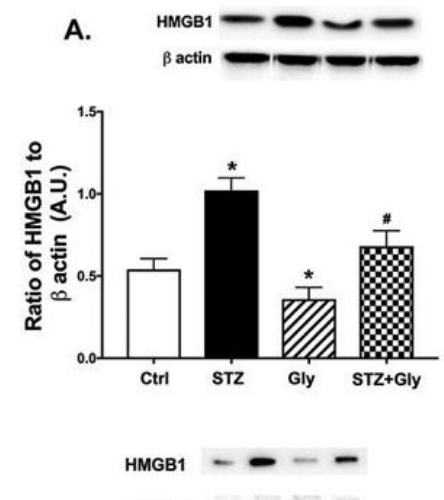

$\beta$ actin

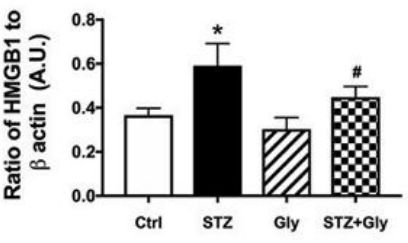

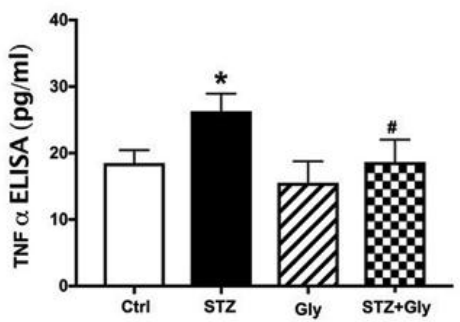

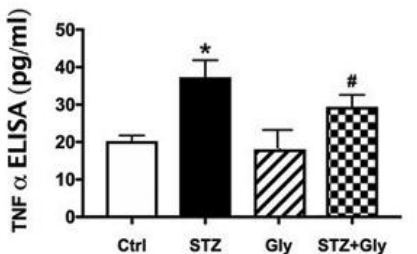

c.
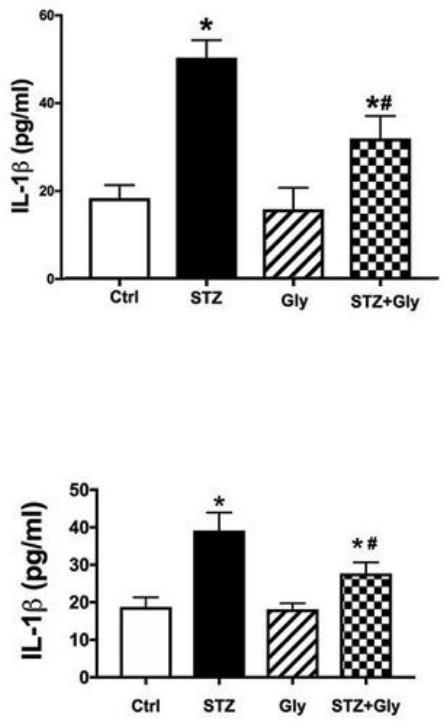

Figure 5. Inflammatory mediators are increased in diabetes. Top panels are at two months and bottom panels are at six months of diabetes. (A) represents high mobility group box 1 (HMGB1), (B) is tumor necrosis factor alpha (TNF $\alpha)$, and (C) is interleukin-1-beta (IL1 $\beta)$ in control mice (Ctrl), control mice treated with glycyrrhizin (Gly), diabetic mice (STZ), and diabetic mice treated with glycyrrhizin $(\mathrm{STZ}+\mathrm{Gly}) .{ }^{*} p<0.05$ vs. ctrl, $\# p<0.05$ vs. Diabetes. $n=5$ for each group.

\subsection{Glycyrrhizin Blocks Both IL1 $\beta$ and Cleaved Caspase 3 in REC Exposed to High Glucose}

Glycyrrhizin reduced TNF $\alpha$ and HMGB1 levels in REC grown in high glucose (Liu, Jiang, and Steinle 2017 [17]), so we decided to further dissect a mechanism for glycyrrhizin by measuring IL1 $\beta$ and cleaved caspase 3 in REC grown in normal and high glucose and treated with glycyrrhizin. Figure 6 demonstrates that REC grown in high glucose medium had increased levels of IL1 $\beta$ and cleaved caspase 3, which agrees with previous work. Similar to the mouse data, glycyrrhizin significantly decreased IL1 $\beta$ levels and cleaved caspase 3 in the REC exposed to high glucose $(p<0.05$ via Kruskal Wallis testing). Combined with our previous studies in the retinal vasculature, glycyrrhizin likely protects the diabetic retina through anti-inflammatory actions.
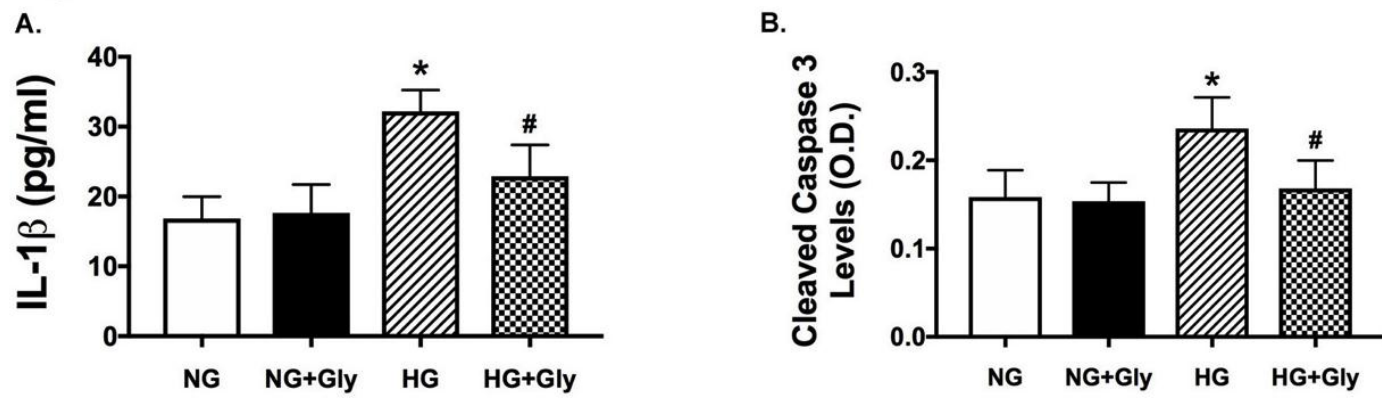

Figure 6. IL1 $\beta$ and cleaved caspase 3 are reduced by glycyrrhizin in retinal endothelial cells (REC) grown in high glucose. REC were grown in normal $(5 \mathrm{mM})$ or high $(25 \mathrm{mM})$ glucose alone or treated with $2 \mathrm{mM}$ glycyrrhizin. (A) shows IL1 $\beta$ and (B) shows cleaved caspase 3. ${ }^{*} p<0.05$ vs. NG, \# $p<0.05$ vs. HG. $n=5$ for each group.

\section{Discussion}

Although a large number of cytokines are involved in diabetic complications, we focused the present study on HMGB1. HMGB1 has been associated with diabetes or high glucose in several retinal 
cell types, including pericytes (Kim et al. 2016 [31]), endothelial cells (Liu, Jiang, and Steinle 2017 [17]), and glial cells and retinal ganglion cells (Santos et al. 2014 [32], Dvoriantchikova et al., 2011 [13]). Inhibition of HMGB1 could be developed as a therapy for diabetic disease. HMGB1 siRNA improved electroretinogram (ERG) measurements, retinal morphology, and reduced retinal cell apoptosis when given intravitreally to diabetic rats or REC grown in high glucose (Jiang and Chen 2017 [33]). Studies in ARPE-19 cells demonstrated that HMGB1 upregulated angiogenic and fibrogenic factors in response to hypoxia (Chang et al. 2017 [34]). Our data support the findings by El-Asrar (2014) showing reduced apoptotic proteins and loss of neuronal proteins at one month of diabetes in rats (Abu El-Asrar et al., 2014 [12]). Unlike their findings in rats, we found that glycyrrhizin reduced blood glucose at two months, but not six months in mice. When we used glycyrrhizin in the drinking water of diabetic mice over six months, we found that glycyrrhizin improved permeability, neuronal, and vascular damage associated with diabetes through a decrease in HMGB1. We previously reported that I/R-induced neuronal and vascular damage was improved after glycyrrhizin (Liu, Jiang, and Steinle 2017 [17]). Our data support the findings of a role of HMGB1 inhibition on retinal ganglion cells in a model of I/R (Dvoriantchikova et al., 2011 [13]). The results of the present study agree with acute experiments in diabetic rats on neuronal protection (Abu El-Asrar et al., 2014 [12]), and expand existing literature to investigate the chronic, preventative actions of glycyrrhizin on both neuronal and vascular changes in the diabetic retina.

We also wanted to investigate potential mechanisms by which glycyrrhizin protected the diabetic retina. Glycyrrhizin reduced TNF $\alpha$ in REC grown in high glucose [17]. We extended those findings in the present study to show that glycyrrhizin also reduced IL1 $\beta$ and cleaved caspase 3 in REC grown in high glucose, suggesting that glycyrrhizin protects the diabetic retina through anti-inflammatory actions. We confirmed that glycyrrhizin significantly reduced HMGB1 after systemic treatment at both two and six months of treatment via drinking water. We also show that TNF $\alpha$ and IL1 $\beta$ were significantly reduced by glycyrrhizin, further suggesting that glycyrrhizin works through anti-inflammatory actions. Our findings agrees with studies in the diabetic kidney that showed reduced inflammatory mediators and renal lesions following glycyrrhizin treatment to diabetic rats (Zhang et al., 2017 [35]). In diabetic mice, other authors reported that glycyrrhizin reduced nuclear factor kappa beta (NFkB) and P38 in diabetic kidneys (Wang et al., 2014 [28]).

In addition to anti-inflammatory actions, we also demonstrated that glycyrrhizin reduced ROS. Diabetes has long been considered a disease resulting from oxidative stress (Brownlee 2001 [30]). Studies on vitreous samples of patients with proliferative diabetic retinopathy demonstrated that the samples had increased HMGB1 levels, as well as markers of oxidative stress (Abu El-Asrar et al., 2017 [36]). The same authors also showed that HMGB1 increased ROS levels in REC (Mohammad et al., 2015 [37]). We found that diabetes significantly increased ROS levels in whole retinal lysates, which was reduced with two and six months of glycyrrhizin treatment. We also found that glycyrrhizin reduced 4-HNE levels in the retinal lysates, suggested reduced lipid peroxidation. Our data agree with findings in the diabetic kidney (Hou et al. 2014 [38]).

Our data strongly suggest that glycyrrhizin is protective to the diabetic retina when given at the initiation of diabetes. This is not ideal for a chronic disease. Long-term interventional studies on the actions of glycyrrhizin when initiated at six months of diabetes are in their initial phases. Additionally, while our studies confirm previous studies on the acute actions of glycyrrhizin on the diabetic retina, we demonstrate the vascular actions of glycyrrhizin for the first time in the diabetic retina. We also provide data suggesting that glycyrrhizin's actions are through the inhibition of inflammatory pathways activated by HMBG1, as well as a reduction in ROS. Future studies will further dissect exact mechanisms by which glycyrrhizin can protect the diabetic retina.

\section{Conclusions}

In conclusion, these data strongly suggest that oral delivery of glycyrrhizin may prevent the complications involved in diabetic retinopathy. While glycyrrhizin is already available for treatment of 
blepharitis and bone metabolism and used as a treatment for a variety of disorders in Asian cultures (Omar et al., 2012 [39]), use in diabetic retinopathy has not been investigated. Nonetheless, glycyrrhizin offers an additional option for therapy development for retinal pathology in diabetes.

Author Contributions: Conceptualization, J.J.S.; methodology, Y.J. and L.L.; validation, L.L., Y.J., J.J.S.; formal analysis, Y.J., L.L.; writing-original draft preparation, J.J.S.; writing—review and editing, J.J.S., L.L.; project administration, J.J.S.; funding acquisition, J.J.S.

Funding: R01EY028442 (J.J.S.), P30EY04068 (Hazlett), and an Unrestricted Grant to the Department of Ophthalmology from Research to Prevent Blindness (Kresge Eye Institute). The funders did not influence these design or execution of these studies.

Conflicts of Interest: The funders had no role in the design of the study; in the collection, analyses, or interpretation of data; in the writing of the manuscript, or in the decision to publish the results.

\section{References}

1. Joussen, A.M.; Poulaki, V.; Le, M.L.; Koizumi, K.; Esser, C.; Janicki, H.; Schraermeyer, U.; Kociok, N.; Fauser, S.; Kirchhof, B.; et al. A central role for inflammation in the pathogenesis of diabetic retinopathy. FASEB J. 2004, 18, 1450-1452. [CrossRef] [PubMed]

2. Tang, J.; Kern, T.S. Inflammation in diabetic retinopathy. Prog. Retin. Eye Res. 2011, 30, 343-358. [CrossRef] [PubMed]

3. Joussen, A.M.; Doehmen, S.; Le, M.L.; Koizumi, K.; Radetzky, S.; Krohne, T.U.; Poulaki, V.; Semkova, I.; Kociok, N. TNF-alpha mediated apoptosis plays an important role in the development of early diabetic retinopathy and long-term histopathological alterations. Mol. Vis. 2009, 15, 1418-1428. [PubMed]

4. Vincent, J.A.; Mohr, S. Inhibition of caspase-1/interleukin-1beta signaling prevents degeneration of retinal capillaries in diabetes and galactosemia. Diabetes 2017, 56, 224-230. [CrossRef] [PubMed]

5. Romeo, G.; Liu, W.-H.; Asnaghi, V.; Kern, T.S.; Lorenzi, M. Activation of nuclear factor-kappaB induced by diabetes and high glucose regulates a proapoptotic program in retinal pericytes. Diabetes 2002, 51, 2241-2248. [CrossRef] [PubMed]

6. Du, Y.; Sarthy, V.P.; Kern, T.S. Interaction between NO and COX pathways in retinal cells exposed to elevated glucose and retina of diabetic rats. Am. J. Physiol. Integr. Comp. Physiol. 2004, 287, R735-R741. [CrossRef] [PubMed]

7. Wang, Y.L.; Wang, K.; Yu, S.J.; Li, Q.; Li, N.; Lin, P.Y.; Li, M.M.; Guo, J.Y. Association of the TLR4 signaling pathway in the retina of streptozotocin-induced diabetic rats. Graefes Arch Clin. Exp. Ophthalmol. 2015, 253, 389-398. [CrossRef] [PubMed]

8. Rajamani, U.; Jialal, I. Hyperglycemia Induces Toll-Like Receptor-2 and -4 Expression and Activity in Human Microvascular Retinal Endothelial Cells: Implications for Diabetic Retinopathy. J. Diabetes Res. 2014, 2014, 1-15. [CrossRef]

9. Berger, E.A.; Carion, T.W.; Jiang, Y.; Liu, L.; Chahine, A.; Walker, R.J.; Steinle, J.J. $\beta$-adrenergic receptor agonist, Compound 49b, inhibits TLR4 signaling pathway in diabetic retina. Immunol. Cell Boil. 2016, 94, 656-661. [CrossRef]

10. Tsung, A.; Tohme, S.; Billiar, T.R. High-mobility group box-1 in sterile inflammation. J. Intern. Med. 2014, 276, 425-443. [CrossRef]

11. Andersson, U.; Tracey, K.J. HMGB1 Is a Therapeutic Target for Sterile Inflammation and Infection. Annu. Rev. Immunol. 2011, 29, 139-162. [CrossRef] [PubMed]

12. Abu El-Asrar, A.M.; Siddiquei, M.M.; Nawaz, M.I.; Geboes, K.; Mohammad, G. The Proinflammatory Cytokine High-Mobility Group Box-1 Mediates Retinal Neuropathy Induced by Diabetes. Mediat. Inflamm. 2014, 2014, 1-10. [CrossRef] [PubMed]

13. Dvoriantchikova, G.; Hernandez, E.; Grant, J.; Santos, A.R.C.; Yang, H.; Ivanov, D. The High-Mobility Group Box-1 Nuclear Factor Mediates Retinal Injury after Ischemia Reperfusion. Investig. Opthalmology Vis. Sci. 2011, 52, 7187-7194. [CrossRef] [PubMed]

14. Ekanayaka, S.A.; McClellan, S.A.; Barrett, R.P.; Kharotia, S.; Hazlett, L.D. Glycyrrhizin Reduces HMGB1 and Bacterial Load in Pseudomonas aeruginosa Keratitis. Investig. Opthalmology Vis. Sci. 2016, 57, 5799-5809. [CrossRef] [PubMed] 
15. Mollica, L.; De Marchis, F.; Spitaleri, A.; Dallacosta, C.; Pennacchini, D.; Zamai, M.; Agresti, A.; Trisciuoglio, L.; Musco, G.; Bianchi, M.E. Glycyrrhizin Binds to High-Mobility Group Box 1 Protein and Inhibits Its Cytokine Activities. Chem. Boil. 2007, 14, 431-441. [CrossRef] [PubMed]

16. Morales-Sosa, M.; Orozco-Suárez, S.; Vega-Garcia, A.; Caballero-Chacón, S.; Feria-Romero, I.A. Immunomodulatory effect of Celecoxib on HMGB1/TLR4 pathway in a recurrent seizures model in immature rats. Pharmacol. Biochem. Behav. 2018, 170, 79-86. [CrossRef] [PubMed]

17. Liu, L.; Jiang, Y.; Steinle, J.J. Inhibition of HMGB1 protects the retina from ischemia-reperfusion, as well as reduces insulin resistance proteins. PLOS ONE 2017, 12, e0178236. [CrossRef]

18. Radu, M.; Chernoff, J. An in vivo Assay to Test Blood Vessel Permeability. J. Vis. Exp. 2013, 73, e50062. [CrossRef]

19. Steinle, J.J.; Kern, T.S.; Thomas, S.A.; McFadyen-Ketchum, L.S.; Smith, C.P. Increased basement membrane thickness, pericyte ghosts, and loss of retinal thickness and cells in dopamine beta hydroxylase knockout mice. Exp. Eye Res. 2009, 88, 1014-1019. [CrossRef]

20. Zhang, Q.; Guy, K.; Pagadala, J.; Jiang, Y.; Walker, R.J.; Liu, L.; Soderland, C.; Kern, T.S.; Ferry, R.; He, H.; et al. Compound 49b Prevents Diabetes-Induced Apoptosis through Increased IGFBP-3 Levels. Investig. Opthalmology Vis. Sci. 2012, 53, 3004-3013. [CrossRef]

21. Liu, L.; Jiang, Y.; Steinle, J.J. Compound 49b Restores Retinal Thickness and Reduces Degenerate Capillaries in the Rat Retina following Ischemia/Reperfusion. PLOS ONE 2016, 11, e0159532. [CrossRef] [PubMed]

22. Veenstra, A.; Liu, H.; Lee, C.A.; Du, Y.; Tang, J.; Kern, T.S. Diabetic retinopathy: retina-specific methods for maintenance of diabetic rodents and evaluation of vascular histopathology and molecular abnormalities. Curr. Protoc. Mouse Boil. 2015, 5, 247-270. [CrossRef] [PubMed]

23. Piippo, N.; Korhonen, E.; Hytti, M.; Kinnunen, K.; Kaarniranta, K.; Kauppinen, A. Oxidative Stress is the Principal Contributor to Inflammasome Activation in Retinal Pigment Epithelium Cells with Defunct Proteasomes and Autophagy. Cell. Physiol. Biochem. 2018, 49, 359-367. [CrossRef] [PubMed]

24. Matsui, S.; Matsumoto, H.; Sonoda, Y.; Ando, K.; Aizu-Yokota, E.; Sato, T.; Kasahara, T. Glycyrrhizin and related compounds down-regulate production of inflammatory chemokines IL-8 and eotaxin 1 in a human lung fibroblast cell line. Int. Immunopharmacol. 2004, 4, 1633-1644. [CrossRef] [PubMed]

25. Abcouwer, S.F.; Lin, C.-M.; Wolpert, E.B.; Shanmugam, S.; Schaefer, E.W.; Freeman, W.; Barber, A.J.; Antonetti, D.A. Effects of Ischemic Preconditioning and Bevacizumab on Apoptosis and Vascular Permeability Following Retinal Ischemia-Reperfusion Injury. Investig. Opthalmol. Vis. Sci. 2010, 51, 5920-5933. [CrossRef] [PubMed]

26. Al-Shabrawey, M.; Rojas, M.; Sanders, T.; Behzadian, A.; El-Remessy, A.; Bartoli, M.; Parpia, A.K.; Liou, G.; Caldwell, R.B. Role of NADPH Oxidase in Retinal Vascular Inflammation. Investig. Opthalmology Vis. Sci. 2008, 49, 3239-3244. [CrossRef] [PubMed]

27. Akutagawa, K.; Fujita, T.; Ouhara, K.; Takemura, T.; Tari, M.; Kajiya, M.; Matsuda, S.; Kuramitsu, S.; Mizuno, N.; Shiba, H.; et al. Glycyrrhizic acid suppresses inflammation and reduces the increased glucose levels induced by the combination of Porphyromonas gulae and ligature placement in diabetic model mice. Int. Immunopharmacol. 2019, 68, 30-38. [CrossRef]

28. Wang, Z.-H.; Hsieh, C.-H.; Liu, W.-H.; Yin, M.-C. Glycyrrhizic acid attenuated glycative stress in kidney of diabetic mice through enhancing glyoxalase pathway. Mol. Nutr. Food Res. 2014, 58, 1426-1435. [CrossRef]

29. Zheng, L.; Du, Y.; Miller, C.; Gubitosi-Klug, R.A.; Ball, S.; Berkowitz, B.A.; Kern, T.S. Critical role of inducible nitric oxide synthase in degeneration of retinal capillaries in mice with streptozotocin-induced diabetes. Diabetologia 2007, 50, 2228. [CrossRef]

30. Brownlee, M. Biochemistry and molecular cell biology of diabetic complications. Nat. 2001, 414, 813-820. [CrossRef]

31. Kim, J.; Kim, C.-S.; Sohn, E.; Kim, J.S. Cytoplasmic translocation of high-mobility group box-1 protein is induced by diabetes and high glucose in retinal pericytes. Mol. Med. Rep. 2016, 14, 3655-3661. [CrossRef] [PubMed]

32. Santos, A.R.C.; Dvoriantchikova, G.; Li, Y.; Mohammad, G.; Abu El-Asrar, A.M.; Wen, R.; Ivanov, D. Cellular Mechanisms of High Mobility Group 1 (HMGB-1) Protein Action in the Diabetic Retinopathy. PLoS ONE 2014, 9, e87574. [CrossRef] [PubMed]

33. Jiang, S.; Chen, $X$. HMGB1 siRNA can reduce damage to retinal cells induced by high glucose in vitro and in vivo. Drug Des. Dev. Ther. 2017, 11, 783-795. [CrossRef] [PubMed] 
34. Chang, Y.-C.; Lin, C.-W.; Hsieh, M.-C.; Wu, H.-J.; Wu, W.-S.; Wu, W.-C.; Kao, Y.-H. High mobility group B1 up-regulates angiogenic and fibrogenic factors in human retinal pigment epithelial ARPE-19 cells. Cell. Signal. 2017, 40, 248-257. [CrossRef] [PubMed]

35. Zhang, H.; Zhang, R.; Chen, J.; Shi, M.; Li, W.; Zhang, X. High Mobility Group Box1 Inhibitor Glycyrrhizic Acid Attenuates Kidney Injury in Streptozotocin-Induced Diabetic Rats. Kidney Blood Press. Res. 2017, 42, 894-904. [CrossRef] [PubMed]

36. Abu El-Asrar, A.M.; Alam, K.; Garcia-Ramirez, M.; Ahmad, A.; Siddiquei, M.M.; Mohammad, G.; Mousa, A.; De Hertogh, G.; Opdenakker, G.; Simó, R. Association of HMGB1 with oxidative stress markers and regulators in PDR. Mol. Vis. 2017, 23, 853-871. [PubMed]

37. Mohammad, G.; Alam, K.; Nawaz, M.I.; Siddiquei, M.M.; Mousa, A.; Abu El-Asrar, A.M. Mutual enhancement between high-mobility group box-1 and NADPH oxidase-derived reactive oxygen species mediates diabetes-induced upregulation of retinal apoptotic markers. J. Physiol. Biochem. 2015, 71, 359-372. [CrossRef]

38. Hou, S.; Zheng, F.; Li, Y.; Gao, L.; Zhang, J. The Protective Effect of Glycyrrhizic Acid on Renal Tubular Epithelial Cell Injury Induced by High Glucose. Int. J. Mol. Sci. 2014, 15, 15026-15043. [CrossRef]

39. Omar, H.R.; Komarova, I.; El-Ghonemi, M.; Fathy, A.; Rashad, R.; Abdelmalak, H.D.; Yerramadha, M.R.; Ali, Y.; Helal, E.; Camporesi, E.M. Licorice abuse: time to send a warning message. Ther. Adv. Endocrinol. Metab. 2012, 3, 125-138. [CrossRef]

(C) 2019 by the authors. Licensee MDPI, Basel, Switzerland. This article is an open access article distributed under the terms and conditions of the Creative Commons Attribution (CC BY) license (http://creativecommons.org/licenses/by/4.0/). 